\title{
EVALUASI KESIAPAN PELAKSANAAN PROGRAM BANTUAN STIMULAN PERUMAHAN SWADAYA BAGI MASYARAKAT BERPENGHASILAN RENDAH
}

\section{EVALUATION OF IMPLEMENTATION READINESS OF SELF-HELP HOUSING STIMULANT ASSISTANCE PROGRAM FOR LOW INCOME COMMUNITY}

\author{
Ahmad Maulana Fajar ${ }^{1 *}$, Gotfridus Goris Seran², Irma Purnamasari ${ }^{3}$ \\ 1,2,3Program Studi Administrasi Publik, Fakultas Ilmu Sosial dan Ilmu Politik, Universitas \\ Djuanda, Jl. Tol Ciawi No. 1, Kotak Pos 35, Bogor 16720 \\ *Korespondensi: Ahmad Maulana Fajar. Email: maulanafajar7788@gmail.com
}

(Diterima: 04-07-2020; Ditelaah; 08-10-2020; Disetujui; 15-12-2020)

\begin{abstract}
The aim of this research is to describe the evaluation of implementation readiness of self-help housing stimulant assistance program for low income community in Ciderum Village, Caringin District, Bogor Regency. The theory used by researchers is based on the input evaluation of Stufflebeam's CIPP (Context, Input, Process, Product) Evaluation Model. This research uses descriptive method to describe the answers of respondents stated in questionnaires, data obtained through interviews, observation, library research and documentation. The sampling technique uses simple random sampling. Data of this research are analyzed by the formula of Weight Mean Score to obtain the mean score. Results of this research indicate that the evaluation of implementation readiness of self-help housing stimulant assistance program for low income community in Ciderum Village, Caringin District, Bogor Regency, is perceived as good. The good perception is based on the mean scores of respondent answers by the village and district apparatuses 3.92 categorized as good and by the community 4.01 categorized as good. Therefore, the evaluation of implementation readiness of self-help housing stimulant assistance program for low income community generally indicates the mean score 3.97 categorized as good. It means that the implementation readiness of self-help housing stimulant assistance program for low income community is well implemented.
\end{abstract}

Key words: Self-Help Housing Stimulant Assistance, Program Evaluation, Low Income Community.

\begin{abstract}
ABSTRAK
Tujuan penelitian ini adalah untuk menggambarkan evaluasi kesiapan pelaksanaan program bantuan stimulan perumahan swadaya bagi masyarakat berpenghasilan rendah di Desa Ciderum Kecamatan Caringin Kabupaten Bogor. Teori yang dipakai peneliti didasarkan pada evaluasi input (masukan) dari Model Evaluasi CIPP (Context, Input, Process, Product) Stufflebeam. Penelitian ini menggunakan metode deskriptif untuk menggambarkan jawaban-jawaban yang diberikan responden dalam kuesioner, data-data yang diperoleh melalui wawancara, observasi, studi pustaka dan dokumentasi. Teknik pengambilan sampel menggunakan simple random sampling. Pengolahan data penelitian menggunakan rumus Weight Mean Score untuk memperoleh skor rerata. Hasil penelitian menunjukkan bahwa evaluasi pelaksanaan program bantuan stimulan perumahan swadaya bagi masyarakat berpenghasilan rendah di Desa Ciderum Kecamatan Caringin Kabupaten Bogor dipersepsikan baik. Penilaian baik ini dilihat dari skor rerata pada jawaban responden pegawai sebesar 3,92 yang dikategorikan baik dan masyarakat sebesar 4,01 yang dikategorikan baik. Dengan demikian, evaluasi kesiapan pelaksanaan program bantuan stimulan perumahan swadaya bagi masyarakat berpenghasilan rendah secara umum menunjukkan nilai rerata 3,97 yang dikategorikan baik, yang berarti bahwa kesiapan pelaksanaan program bantuan stimulan perumahan swadaya bagi masyarakat berpenghasilan rendah dilaksanakan dengan baik.
\end{abstract}

Kata kunci: Bantuan Stimulan Perumahan Swadaya, Evaluasi Program, Masyarakat Berpenghasilan Rendah.

Fajar, Ahmad Maulana; Seran, Gotfridus Goris \& Purnamasari, Irma. (2021). Evaluasi Kesiapan Pelaksanaan Program Bantuan Stimulan Perumahan Swadaya Bagi Masyarakat Berpenghasilan Rendah. Jurnal GOVERNANSI, 7(1): 19-28. 


\section{PENDAHULUAN}

Pembangunan pada hakikatnya adalah perubahan yang terencana dari suatu keadaan ke keadaan lainnya yang dinilai lebih baik. Adapun wujud kebijakan yang bisa dilakukan adalah dengan memberikan suatu kebijakan untuk meningkatkan kesejahteraan masyarakat. Pasal 28H UndangUndang Dasar Negara Republik Indonesia Tahun 1945 menetapkan bahwa setiap orang memiliki hak berkehidupan sejahtera dimana salah satunya diukur dengan sehat secara lahir dan bathin, dengan mempunyai sebuah tempat hunian yang layak, tentunya memberikan pengakuan sosial dengan status yang diakui dan memberikan peluang serta kesempatan terhadap peningkatan program kesejahteraan, selain itu juga mampu memberikan kesempatan peluang usaha bagi orang yang membutuhkan hunian yang layak.

Perumahan merupakan salah satu unsur dan indikator kebutuhan penting bagi kehidupan manusia dan tentunya merupakan pengejawantahan diri manusia, baik sebagai pribadi maupun sebagai suatu kesatuan dengan lingkungan alamnya. Berdasarkan Undang-Undang Dasar 1945 tentang Hak Asasi Manusia, Pasal 28H dijelaskan bahwa tempat tinggal dan lingkungan yang layak adalah hak bagi setiap orang. Setiap orang berkesempatan mendapatkan kehidupan sejahtera secara lahir dan batin, dan mempunyai hunian yang nyaman atau layak, serta mendapatkan kehidupan sosial yang baik dan sehat serta berkesempatan memperoleh pelayanan kesehatan.

Rumah memiliki fungsi yang begitu besar bagi manusia dalam menjalankan kehidupan sehari-hari. Dengan memiliki rumah yang layak huni, maka seseorang ataupun sekelompok orang dapat terlindungi dari berbagai macam bahaya. Berdasarkan Undang-Undang Nomor 1 Tahun 2011 tentang Perumahan dan Kawasan Permukiman yang merupakan hasil revisi UU Nomor 4 Tahun 1992 tentang Perumahan dan Permukiman lebih ditegas- kan dengan penjelasan bahwa rumah merupakan unsur atau indikator terpenting bagi kebutuhan primer manusia dengan tujuan untuk memberikan peningkatan yang lebih baik dan memberikan pemerataan kesejahteraan bagi kehidupan rakyat atau manusia. Salah satu tindakan yang nyata dan berguna bagi kehidupan telah mampu dan memberikan hasrat keinginan hunian rumah bagi setiap masyarakat adalah dengan peningkatan dan pembangunan hunian rumah dan kawasan permukiman. Pada dasarnya, untuk menyediakan tempat atau lokasi untuk peningkatan dan pembangunan hunian rumah yang sejahtera dilengkapi dengan utilitas yang memadai dan sarana prasarana serta terjangkau demi terciptanya tujuan yang baik.

Pemerintah merumuskan programprogram yang berupaya untuk mengatasi masalah kemiskinan dengan memberikan hasil pemberdayaan secara berkelanjutan. Adapun program yang dihasilkan pemerintah bukan hanya satu hal terhadap bantuan stimulan usaha ekonomi, namun juga program untuk kebutuhan atau keinginan tempat tinggal atau hunian yang nyaman dan layak bagi masyarakat tidak mampu pun tidak luput dari perhatian pemerintah salah satunya adalah program bantuan stimulan perumahan swadaya.

Pemerintah melalui Kementerian Pekerjaan Umum dan Perumahan Rakyat Republik Indonesia membuat suatu program untuk mengatasi kemiskinan, yaitu program bantuan stimulan perumahan swadaya untuk masyarakat berpenghasilan rendah. Adapun program bantuan stimulan perumahan swadaya diatur dalam Peraturan Menteri Pekerjaan Umum dan Perumahan Rakyat Republik Indonesia Nomor: 07/PRT/M/2018. Yang dimaksud dengan bantuan stimulan perumahan swadaya adalah bantuan pemerintah untuk masyarakat atau warga yang penghasilannya minim demi membangun dan meningkatkan yang lebih baik untuk keswadayaan dalam peningkatan kualitas hunian rumah dan pembangunan rumah beserta sarana, 
prasarana, dan utilitas umum. Masyarakat berpenghasilan rendah adalah masyarakat yang mempunyai daya beli yang kurang dan terbatas sehingga perlu mendapat dukungan pemerintah untuk memperoleh rumah.

Tujuan adanya program bantuan stimulan perumahan swadaya bagi masyarakat berpenghasilan rendah adalah untuk memberdayakan masyarakat yang berpenghasilan rendah agar mampu membangun atau meningkatkan kualitas rumah secara swadaya sehingga dapat menghuni rumah yang layak dalam lingkungan yang sehat dan aman. Ciderum adalah salah satu desa di Kecamatan Caringin Kabupaten Bogor yang mendapatkan program bantuan stimulan perumahan swadaya dari Kementerian Pekerjaan Umum dan Perumahan Rakyat Republik Indonesia dengan jumlah penerima bantuan sebanyak 80 orang/ kepala keluarga, sebagaimana dinyatakan dalam Keputusan Pejabat Pembuat Komitmen Rumah Swadaya Wilayah II Satuan Kerja Penyediaan Rumah Swadaya Nomor: 148/KPTS/PPKRS-Wilayah2/2019 tentang Penerima Bantuan Stimulan Perumahan Swadaya Berupa Uang Tahun Anggaran 2019, Desa Ciderum, Kecamatan Caringin, Kabupaten Bogor. Data Desa Ciderum menunjukkan bahwa rumah tidak layak huni (RTLH) sebanyak 252 orang atau kepala keluarga. Dari 80 orang/kepala keluarga yang menerima berarti masih terdapat 172 orang/kepala keluarga yang belum menerima bantuan, apabila dipersentasikan, maka orang/kepala keluarga yang mendapatkan bantuan hanya 32\% sedangkan $68 \%$ yang belum memperoleh bantuan.

Berdasarkan latar belakang masalah tersebut, maka peneliti tertarik untuk meneliti evaluasi kesiapan pelaksanaan program bantuan stimulan perumahan swadaya bagi masyarakat berpenghasilan rendah dengan menggunakan evaluasi input (masukan) dari Stufflebeam tentang Model Evaluasi CIPP (Context, Input, Process \& Product).

\section{MATERI DAN METODE}

\section{Konsep/Teori Yang Relevan}

Stufflebeam dalam Arikunto (2004: 1) mengartikan evaluasi sebagai proses penggambaran, pencarian dan pemberian informasi yang bermanfaat untuk pengambil keputusan dalam menentukan alternatif keputusan. Stufflebeam dan Shinkifiled dalam Widoyoko (2010: 3) menyatakan bahwa evaluation is the process of delineating, obtaining, and providing descriptive and judgmental information about the worth and merit of some object's goals, design, implementation, and impact in order to guide decision making, serve needs for accountability, and promote understanding of the involved phenomena.

Penelitian Dehani, Hernawan dan Purnamasari (2018), Wulandari, Salbiah dan Seran (2017) menggunakan enam kriteria, yaitu efektifitas, efisiensi, kecukupan, pemerataan, responsivitas dan ketepatan, untuk melakukan evaluasi pelaksanaan program di sektor publik. Peneliti menggunakan evaluasi input (masukan) dari Model Evaluasi CIPP (Context, Input, Process, Product) Stufflebeam. Stufflebeam (2003: 2) mengemukakan Model Evaluasi CIPP sebagai berikut:

The model core concepts are denoted by acronym CIPP, which stands for evaluations of an entity's context, input, process, and product. Context evaluations assess needs, problems, assets, and opportunities to help decicions makers define goals and priorities and help broader group of user judge goals, priorities, and outcomes. Input evaluations assess alternative approaches, competing action plans, and budgets for their feasibility and potential cost-effectiveness to meet targeted needs and achieved goals. Decision makers use input evaluations in choosing among competing plans, writing funding proposals, allocation resources, assigning staff, scheduling work, and ultimately in helping others judge an effort's plans and budget. 
Menurut Stufflebeam, kesiapan pelaksanaan program dapat dievaluasi dengan menggunakan sembilan indikator sebagai berikut:

1. Syarat Peserta Program, yaitu bagian dari perencanaan dimana menjadi unsur wajib bagi peserta atau penerima program.

2. Proses Rekrutmen Peserta, yaitu proses mencari, menemukan mengajak dan menetapkan sejumlah orang, baik dari dalam maupun dari luar sebagai calon tertentu dengan karakteristik tertentu sesuai apa yang diharapkan (Samsudin, 2006).

3. Jumlah Peserta, yaitu bagian dari perencanaan yang ditetapkan oleh penyelenggara dalam banyaknya suatu peserta atau penerima program.

4. Kriteria Penyelenggara, yaitu jenis-jenis proses atau cara perbuatan penyelenggara dalam program.

5. Kriteria Pengawas, yaitu jenis-jenis pengontrol dalam tugas yang diberikan mandat oleh pemangku kepentingan (stakeholder).

6. Jumlah Pengawas, yaitu mengukur penilaian pekerja pegawai dimana menjadi salah satu unsur keberhasilan dalam kinerja dimana kuantitas pekerja menjadi tolok ukur atau barometer (Tiffin dan McCormick, 1974; Sukasah, 2005).

7. Waktu Pelaksanaan, yaitu usaha menggerakkan anggota kelompok sedemikian rupa hingga mereka berkeinginan dan berusaha mencapai sasaran (Terry, 1986). Dalam hal ini, waktu pelaksanaan berhubungan dengan usaha untuk menjalankan apa yang sudah direncanakan sebelumnya melalui pengarahan dengan tujuan agar mendapat hasil yang optimal dan sesuai dengan tujuan yang telah ditetapkan.

8. Sumber Program, yaitu asal suatu program dari pemangku kepentingan program.
9. Sumber Dana Program, yaitu asal keuangan dari pemangku program hal ini tentunya menjadi suatu indikator keberhesilan dalam mengevaluasi program agar mencapai tujuan yang diharapkan (Arikunto, 2008: 28, 4647).

\section{Metode}

Metode yang digunakan dalam penelitian ini adalah metode deskriptif (Sugiono, 2014) untuk menggambarkan evaluasi kesiapan pelaksanaan program bantuan stimulan perumahan swadaya bagi masyarakat berpenghasilan rendah di Desa Ciderum Kecamatan Caringin Kabupaten Bogor. Responden penelitian dibagi ke dalam dua kelompok sasaran, yaitu pegawai (desa/kecamatan) dan masyarakat (peserta/penerima bantuan stimulan perumahan swadaya). Teknik pengambilan sampel menggunakan simple random sampling (Sugiyono, 2017: 81).

Penelitian ini membutuhkan data primer dan data sekunder. Data sekunder dikumpulkan dari studi kepustakaan (library research) dan dokumentasi. Teknik ini memperoleh data sekunder yang dilakukan dengan cara membaca, mempelajari, mengutip dan merangkum isi buku, jurnal, peraturan perundang-undangan dan dokumen yang relevan. Sedangkan data primer dikumpulkan dari studi lapangan (field research). Teknik ini memperoleh data primer dengan cara pengamatan langsung (observation), wawancara (interview), dan penyebaran angket/kuesioner (questionaires) kepada responden penelitian.

Data penelitian dianalisis secara kualitatif, yaitu dengan mengelompokkan data berdasarkan indikator dan jawaban responden, mentabulasi data dan kemudian melakukan perhitungan dengan tujuan agar bisa menjawab permasalahan penelitian. Adapun kuesioner disusun dengan menggunakan skala Likert dan setiap jawaban responden diberi penilaian berdasarkan lima tingkatan bobot nilai dari 1-5 secara 
ordinal, mulai dari sangat baik dengan skor 5 , baik dengan skor 4 , cukup baik dengan skor 3 , tidak baik dengan skor 2 dan sangat tidak baik dengan skor 1 . Adapun perhitungannya menggunakan Rumus Weight Mean Score (WMS) untuk mendapatkan skor rerata (mean/M) terhadap jawaban responden penelitian. Skor rerata tersebut diinterpretasi berdasarkan kategori berikut: 1,00-1,79 (sangat tidak baik), 1,80-2,59 (tidak baik), 2,60-3,39 (cukup baik), 3,404,19 (baik), dan 4,20-5,00 (sangat baik) (Ridwanullah, et al, 2019).

\section{HASIL DAN PEMBAHASAN}

Hasil penelitian mengenai evaluasi kesiapan pelaksanaan program bantuan stimulan perumahan swadaya bagi masyarakat berpenghasilan rendah di Desa Ciderum Kecamatan Caringin Kabupaten Bogor dideskripsikan sebagai berikut:

\section{Syarat Peserta Program}

Hasil evaluasi kesiapan pelaksanaan program bantuan stimulasi perumahan swadaya bagi masyarakat berpenghasilan rendah dilihat dari indikator syarat peserta program menunjukkan:

(1) Rerata skor penilaian pegawai 4.00 dengan kriteria penilaian baik.

(2) Rerata skor penilaian masyarakat 4,17 dengan kriteria penilaian baik.

Indikator syarat peserta program wajib bagi penerima atau peserta program BSPS kesiapan pelaksanaan program bantuan stimulan perumahan swadaya di Desa Ciderum Kecamatan Caringin Kabupaten Bogor. Syarat peserta program adalah mempunyai KTP (Kartu Tanda Penduduk), tanah yang sah, rumah tidak layak, belum pernah mendapatkan bantuan tentang rumah, mempunyai penghasilan yang telah ditentukan, berswadaya, dan membuat kelompok. Kesiapan pelaksanaan mengacu pada peraturan yang ditentukan, yaitu Peraturan Menteri PUPR RI Nomor: 07/PRT/M/2018 tentang Bantuan Stimulasi Perumahan Swadaya. Dapat diambil kesimpulan bahwa indikator syarat peserta program dari kesiapan pelaksanaan program sudah baik dibuktikan dengan hasil responden masyarakat dan pegawai dengan kriteria baik.

\section{Proses Rekrutmen Peserta}

Hasil evaluasi kesiapan program bantuan stimulasi perumahan swadaya bagi masyarakat berpenghasilan rendah dilihat dari indikator proses rekrutmen peserta menunjukkan:

(1) Rerata skor penilaian pegawai 4,25 dengan kriteria penilaian sangat baik.

(2) Rerata skor penilaian masyarakat 3,88 dengan kriteria penilaian baik.

Indikator proses rekrutmen peserta adalah proses untuk memilih peserta atau penerima program bantuan stimulan perumahan swadaya. Dalam kesiapan pelaksanaan di Desa Ciderum Kecamatan Caringin Kabupaten Bogor dalam rekrutmen peserta tahapannya adalah mendata rumah di setiap RT/RW yang tidak layak, verifikasi data, pemangku kepentingan mengecek langsung ke lapangan, kemudian diambillah data peserta yang paling membutuhkan. Dalam mengevaluasi kesiapan pelaksanaan program dalam indikator rekrutmen peserta sudah baik. Hal tersebut dibuktikan dengan penilai responden masyarakat dan pegawai dengan kriteria baik.

\section{Jumlah Peserta}

Hasil evaluasi kesiapan pelaksanaan program bantuan stimulasi perumahan swadaya bagi masyarakat berpenghasilan rendah dilihat dari indikator jumlah peserta menunjukkan:

(1) Rerata skor penilaian pegawai 3,50 dengan kriteria penilaian baik.

(2) Rerata skor penilaian masyarakat 3,04 dengan kriteria penilaian Cukup baik.

Indikator jumlah peserta menjelaskan jumlah total peserta program yang mendapatkan program bantuan stimulan perumahan swadaya dalam kesiapan pelaksanaan program sudah baik. Hal ini dibuktikan dengan jawaban responden 
pegawai dengan kriteria baik. Namun dalam membantu masyarakat berpenghasilan rendah, program ini belum mampu sepenuhnya. Hal ini dibuktikan dalam program bantuan stimulan perumahan swadaya di Desa Ciderum Kecamatan Caringin Kabupaten Bogor yang mendapat-kan bantuan hanya 80 orang/kepala keluarga dari jumlah total rumah yang tidak layak sebanyak 252 orang/kepala keluarga sebagaimana terungkap dari penilaian responden masyarakat dengan kriteria cukup baik.

\section{Kriteria Penyelenggara}

Hasil evaluasi kesiapan pelaksanaan program bantuan stimulasi perumahan swadaya bagi masyarakat berpenghasilan rendah dilihat dari indikator kriteria penyelenggara menunjukkan:

(1) Rerata skor penilaian pegawai 4,00 dengan kriteria penilaian baik.

(2) Rerata skor penilaian masyarakat 4,11 dengan kriteria penilaian baik.

Indikator penyelenggara adalah prosedur dan proses program bantuan stimulan perumahan swadaya, dimana dalam menilai kesiapan pelaksanaan program sudah baik, hal tersebut dibuktikan dengan jawaban responden pegawai dan masyarakat dengan kriteria baik dan sudah mengacu pada Peraturan Menteri PUPR RI Nomor: 07/PRT/M/2018 tentang Bantuan Stimulan Perumahan Swadaya, dimana kriteria penyelenggara ialah adanya usulan tempat/ lokasi. Penetapan tempat, mengumpulkan masyarakat, penetapan calon peserta atau penerima, pencairan baik uang atau barang dan terakhir adalah pelaporan. Oleh sebab itu, indikator kriteria penyelenggara sudah baik dalam membantu masyarakat berpenghasilan rendah.

\section{Kriteria Pengawas}

Hasil evaluasi kesiapan pelaksanaan program bantuan stimulasi perumahan swadaya bagi masyarakat berpenghasilan rendah dilihat dari indikator kriteria pengawas menunjukkan:
(1) Rerata skor penilaian pegawai 3,75 dengan kriteria penilaian baik.

(2) Rerata skor penilaian masyarakat 4,06 dengan kriteria penilaian baik.

Indikator kriteria pengawas membahas kegiatan pengawas dan penunjukan pengawas dalam kesiapan pelaksanaan program sudah baik. Hal ini dibuktikan dengan jawaban responden masyarakat dan pegawai dengan kriteria penilaian baik dan sudah mengacu pada Peraturan Menteri PUPR RI Nomor: 07/PRT/M/2018 tentang Bantuan Stimulan Perumahan Swadaya, dimana kriteria pengawas ditinjau dari tugasnya adalah mengawasi jalannya program mulai dari perencanaan sampai laporan. Adapun pengawas dalam ini dipilih oleh KPA (Kuasa Pengguna Anggaran) atau dipilih langsung oleh pemangku kepentingan program bantuan stimulan perumahan swadaya ini. Oleh karena itu, kesiapan pelaksanaan program dalam indikator kriteria pengawas sudah baik.

\section{Jumlah Pengawas}

Hasil evaluasi kesiapan pelaksanaan program bantuan stimulasi perumahan swadaya bagi masyarakat berpenghasilan rendah dilihat dari indikator jumlah pengawas menunjukkan:

(1) Rerata skor penilaian pegawai 3,75 dengan kriteria penilaian baik.

(2) Rerata skor penilaian masyarakat 4,15. dengan kriteria penilaian baik.

Indikator jumlah pengawas membahas kuantitas yang mengamati dalam proses pelaksanaan program, dimana dalam hal ini yang mengawasi program bantuan stimulan perumahan swadaya di Desa Ciderum Kecamatan Caringin Kabupaten Bogor terdapat dua pengawas dari pihak desa dan kecamatan dari unsur internal dan eksternal dari Kementerian PUPR RI sendiri Inspektorat, DKPP Kabupaten Bogor. Penilaian terhadap kesiapan pelaksanaan program bantuan stimulan perumahan swadaya tersebut sudah dikatakan baik. Hal ini dibuktikan dengan penilaian responden 
pegawai dan masyarakat dengan kriteria penilaian baik.

\section{Waktu Pelaksanaan}

Hasil evaluasi kesiapan pelaksanaan program bantuan stimulasi perumahan swadaya bagi masyarakat berpenghasilan rendah dilihat dari indikator waktu pelaksanaan menunjukkan:

(1) Rerata skor penilaian pegawai 3,25 dengan kriteria penilaian cukup baik.

(2) Rerata skor penilaian masyarakat 3,97 dengan kriteria penilaian baik.

Indikator waktu pelaksanaan dengan tujuan mengetahui waktu pelaksanaan proses program. Dalam pelaksanaan di Desa Ciderum selama dua bulan dimulai dari surat keputusan keluar, yaitu tanggal $13 \mathrm{Mei}$ 2019. Dalam menilai kesiapan pelaksanaan program bantuan stimulan perumahan swadaya di Desa Ciderum Kecamatan Caringin Kabupaten Bogor, indikator waktu pelaksanaan belum sepenuhnya baik. Hal ini dibuktikan dengan tahap kedua penerima diberi waktu hanya satu bulan dalam pelaksanaannya dan rendahnya responden pegawai dalam menilai kendatipun dengan kriteria cukup baik.

\section{Sumber Program}

Hasil evaluasi kesiapan pelaksanaan program bantuan stimulasi perumahan swadaya bagi masyarakat berpenghasilan rendah dilihat dari indikator sumber program menunjukkan:

(1) Rerata skor penilaian pegawai 4,25 dengan kriteria penilaian sangat baik.

(2) Rerata skor penilaian masyarakat 4,40 dengan kriteria penilaian sangat baik.

Indikator sumber program menjelaskan asal program bantuan stimulan perumahan swadaya. Pemangku kepentingannya adalah pemerintah melalui Kementerian PUPR yang menjadi sumber program tersebut dan sejauh ini penilaian kesiapan pelaksanaan sudah baik. Hal ini dibuktikan dengan penilaian responden pegawai dan masyarakat dengan kriteria sangat baik.

\section{Sumber Dana Program}

Hasil evaluasi kesiapan pelaksanaan program bantuan stimulasi perumahan swadaya bagi masyarakat berpenghasilan rendah dilihat dari indikator sumber dana program menunjukkan:

(1) Rerata skor penilaian pegawai 4,50 dengan kriteria penilaian sangat baik.

(2) Rerata skor penilaian masyarakat 4,35 dengan kriteria penilaian sangat baik.

Indikator sumber program menjelaskan asal keuangan (budgeting) dari program bantuan stimulan perumahan swadaya. Dalam hal ini, pemangku kepentingannya adalah pemerintah melalui Kementerian PUPR menjadi sumber program tersebut dan sejauh ini penilaian kesiapan pelaksanaan sudah baik. Hal ini dibuktikan dengan penilaian responden pegawai dan masyarakat dengan kriteria sangat baik.

Ukuran keseluruhan indikator dari evaluasi input (masukan) dilihat dalam Tabel 1 dan Tabel 2 di bawah ini.

Tabel 1. Penilaian Rerata Skor Jawaban Responden Pegawai untuk Evaluasi Input (Masukan)

\begin{tabular}{llcc}
\hline No. & Indikator & Rerata & Kriteria \\
\hline 1. & $\begin{array}{l}\text { Syarat Peserta } \\
\text { Program }\end{array}$ & 4,00 & Baik \\
\hline 2. & $\begin{array}{l}\text { Proses Rekrutmen } \\
\text { Peserta }\end{array}$ & 4,25 & $\begin{array}{c}\text { Sangat } \\
\text { Baik }\end{array}$ \\
\hline 3. & Jumlah Peserta & 3,50 & Baik \\
\hline 4. & $\begin{array}{l}\text { Kriteria } \\
\text { Penyelenggara }\end{array}$ & 4,00 & Baik \\
\hline 5. & Kriteria Pengawas & 3,75 & Baik \\
\hline 6. & Jumlah Pengawas & 3,75 & Baik \\
\hline 7. & Waktu Pelaksanaan & 3,25 & $\begin{array}{c}\text { Cukup } \\
\text { Baik }\end{array}$ \\
\hline 8. & Sumber Program & 4,25 & $\begin{array}{c}\text { Sangat } \\
\text { Baik }\end{array}$ \\
\hline 9. & $\begin{array}{l}\text { Sumber Dana } \\
\text { Program }\end{array}$ & 4,50 & $\begin{array}{c}\text { Sangat } \\
\text { Baik }\end{array}$ \\
\hline & Rerata Skor & 3,92 & Baik \\
\hline
\end{tabular}

Tabel 1 menunjukkan rerata skor dari evaluasi input (masukan) dalam evaluasi kesiapan pelaksanaan program bantuan stimulan perumahan swadaya bagi masyarakat berpenghasilan rendah di Desa Ciderum Kecamatan Caringin Kabupaten 
Bogor. Skor rerata pada jawaban responden pegawai desa dan kecamatan sebesar 3,92 yang berada pada kriteria penafsiran kategori baik.

Tabel 2. Penilaian Rerata Skor Jawaban Responden Masyarakat untuk Evaluasi Input (Masukan)

\begin{tabular}{llcc}
\hline No. & Indikator & Rerata & Kriteria \\
\hline 1. & $\begin{array}{l}\text { Syarat Peserta } \\
\text { Program }\end{array}$ & 4,17 & Baik \\
\hline 2. & $\begin{array}{l}\text { Proses Rekrutmen } \\
\text { Peserta }\end{array}$ & 3,88 & Baik \\
\hline 3. & Jumlah Peserta & 3,04 & $\begin{array}{c}\text { Cukup } \\
\text { Baik }\end{array}$ \\
\hline 4. & $\begin{array}{l}\text { Kriteria } \\
\text { Penyelenggara }\end{array}$ & 4,11 & Baik \\
\hline 5. & Kriteria Pengawas & 4,06 & Baik \\
\hline 6. & Jumlah Pengawas & 4,15 & Baik \\
\hline 7. & Waktu Pelaksanaan & 3,97 & Baik \\
\hline 8. & Sumber Program & 4,40 & $\begin{array}{c}\text { Sangat } \\
\text { Baik }\end{array}$ \\
\hline 9. & $\begin{array}{l}\text { Sumber Dana } \\
\text { Program }\end{array}$ & 4,35 & $\begin{array}{c}\text { Sangat } \\
\text { Baik }\end{array}$ \\
\hline & Rerata Skor & 4,01 & Baik \\
\hline
\end{tabular}

Tabel 2 menunjukkan rerata skor dari evaluasi input (masukan) dalam evaluasi kesiapan pelaksanaan program bantuan stimulan perumahan swadaya bagi masyarakat berpenghasilan rendah di Desa Ciderum Kecamatan Caringin Kabupaten Bogor. Skor rerata pada jawaban responden masyarakat penerima bantuan stimulan perumahan swadaya sebesar 4,01 yang berada pada kriteria penafsiran kategori baik.

Evaluasi kesiapan pelaksanaan program bantuan stimulan perumahan swadaya bagi masyarakat berpenghasilan rendah di Desa Ciderum Kecamatan Caringin Kabupaten Bogor menunjukkan bahwa hasil rerata perhitungan jawaban responden pegawai untuk evaluasi input (masukan) memperoleh angka tertinggi rerata sebesar 4,50 dengan kriteria penafsiran sangat baik pada indikator sumber dana program.

Hasilnya berbeda dengan jawaban responden masyarakat (peserta atau penerima). Evaluasi kesiapan pelaksanaan program bantuan stimulasi perumahan swadaya bagi masyarakat berpenghasilan rendah di Desa Ciderum Kecamatan Caringin Kabupaten Bogor menunjukkan angka tertinggi rerata sebesar 4,40 dengan kriteria penafsiran sangat baik pada indikator sumber program.

Adapun angka kriteria penafsiran terendah bagi responden pegawai (Desa dan Kecamatan Caringin Kabupaten Bogor) pada indikator jumlah peserta dengan rerata skor 3,50 kriteria penafsiran baik. Sedangkan untuk responden masyarakat (peserta atau penerima) hasilnya sama, hasil terendah pada indikator jumlah peserta, sejatinya yang membedakan kriteria penafsiran dan rerata skor yang memperoleh 3,04 dengan nilai cukup baik.

Berdasarkan hasil rekapitulasi tersebut, maka secara umum evaluasi kesiapan pelaksanaan program bantuan stimulan perumahan swadaya bagi masyarakat berpenghasilan rendah di Desa Ciderum Kecamatan Caringin Kabupaten Bogor yang dilihat berdasarkan 9 indikator (syarat peserta program, proses rekrutmen peserta, jumlah peserta, kriteria penyelenggara, kriteria pengawas, jumlah pengawas, waktu pelak-sanaan, sumber program dan sumber dana program) menunjukkan nilai rerata 3,97 yang berada pada kriteria penafsiran kategori baik. Menurut evaluasi/penilaian pegawai dan masyarakat, hal ini menunjukkan implementasi yang baik dalam kesiapan pelaksanaan program bantuan stimulan perumahan swadaya bagi masyarakat berpenghasilan rendah di Desa Ciderum Kecamatan Caringin Kabupaten Bogor.

\section{KESIMPULAN DAN IMPLIKASI}

\section{Kesimpulan}

Hasil penelitian tentang evaluasi kesiapan pelaksanaan program bantuan stimulan perumahan swadaya bagi masyarakat berpenghasilan rendah di Desa Ciderum Kecamatan Caringin Kabupaten Bogor berdasarkan sembilan indikator, yaitu syarat peserta program, proses rekrutmen peserta, jumlah peserta, kriteria penyelenggara, kriteria pengawas, jumlah 
pengawas, waktu pelaksanaan, sumber program dan sumber dana program, menunjukkan: (1) skor rerata pada jawaban responden pegawai sebesar 3,92 yang berada pada kriteria penafsiran kategori baik, (2) skor rerata pada jawaban responden masyarakat sebesar 4,01 yang berada pada kriteria penafsiran kategori baik. Secara umum, evaluasi kesiapan pelaksanaan program bantuan stimulan perumahan swadaya bagi masyarakat berpenghasilan rendah di Desa Ciderum Kecamatan Caringin Kabupaten Bogor menunjukkan nilai rerata 3,97 yang berada pada kriteria penafsiran kategori baik. Hal ini menunjukkan bahwa kesiapan pelaksanaan program bantuan stimulan perumahan swadaya bagi masyarakat berpenghasilan rendah di Desa Ciderum Kecamatan Caringin Kabupaten Bogor menurut evaluasi/penilaian pegawai dan masyarakat dilaksanakan dengan baik.

\section{Implikasi}

Secara teoritis, evaluasi kesiapan program untuk mengukur keberhasilan dari aspek masukan (input) sangat penting bagi sektor publik. Teori evaluasi yang dipakai adalah evaluasi Model CIPP Stufflebeam dengan melihat dari dimensi input kesiapan pelaksanaan kebijakan/program. Penggunaan indikator-indikator evaluasi masukan memberikan pembuktian teori dimaksud.

Secara praktis, hasil penelitian ini dapat memberikan manfaat sebagai bahan masukan kebijakan/program yang dirumuskan dan diimplementasikan di sektor publik, termasuk program bantuan stimulasi perumahan swadaya bagi masyarakat berpenghasilan rendah di Desa Ciderum Kecamatan Caringin Kabupaten Bogor.

\section{DAFTAR PUSTAKA}

\section{Buku}

Arikunto, Suharsimi. (2004). Dasar-dasar Evaluasi Pendidikan. Jakarta: Bumi Aksara.
Arikunto, Suharsimi dan Jabar, Cepi Safrudin Abdul. (2009). Evaluasi Program Pendidikan. Jakarta: Bumi Aksara.

Sadili, Samsudin. (2006). Manajemen Sumber Daya Manusia. Bandung: Pustaka Setia.

Sugiyono. (2017). Metode Penelitian Kuantitatif, Kualitatif, dan $R \& D$. Bandung: Alfabeta.

Suharto. Edi. (2007). Kebijakan Sosial sebagai Kebijakan Publik. Bandung: Alfabeta.

Sukasah, Taufik. (2005). Pengaruh Proses Rekrutmen, Seleksi dan Penempatan terhadap Kinerja Pegawai di Deputi Administrasi Sekretariat Negara RI. Depok: Universitas Indonesia.

Stufflebeam, D. L. (2003). The CIPP Model for Evalution. The article presented at the 2003 annual conference of the Oregn Program Evaluator Network (Open) 3 October.

Tiffin, Joseph \& Ernest McCormick. (1974). Industrial Psychology. India: PrenticeHall.

Widoyoko, Eko Putro. (2010). Evaluasi Program Pembelajaran. Yogyakarta: Pustaka Pelajar.

\section{Jurnal}

Dehani, Maya; Hernawan, Denny \& Purnamasari, Irma. (2018). "Evaluasi Program Keluarga Harapan (PKH) di Kecamatan Bogor Selatan Kota Bogor". Jurnal GOVERNANSI, 4(1). http://dx. doi.org/10.30997/jgs.v4i1.1140.

Ridwanullah, Muhammad, et al. (2019). "Implementation of e-Governance to Improve the Civil Administration Service Quality in Public Sector". International Journal of Sciences: Basic and Applied Research (IJSBAR), 48(3): 168-178. https://gssrr.org/index. php/JournalOfBasicAndApplied/articl e/view/10319. 
Wulandari, Retno; Salbiah, Euis \& Seran, G. Goris. (2017). "Evaluasi Road Safety Patnership Action Police Goes to School di SMA Negeri 6 dan SMK Pembangunan Kota Bogor". Jurnal GOVERNANSI, 3(1). http://dx.doi.org/ 10.30997/jgs.v3i1.813.

\section{Peraturan Perundang-undangan}

Keputusan Pejabat Pembuat Komitmen Rumah Swadaya Wilayah II Satker Penyediaan Rumah Swadaya Nomor: 148/KPTS/PPKRS-Wilayah2/2019 tentang Penerima Program BSPS Berupa Uang Tahun Anggaran 2019 Desa Ciderum Kecamatan Caringin Kabupaten Bogor.

Peraturan Menteri Pekerjaan Umum dan Perumahan Rakyat Republik Indonesia Nomor: 07/PRT/M/2018 tentang Bantuan Stimulan Perumahan Swadaya.

Undang-Undang Dasar Negara Republik Indonesia Tahun 1945. 